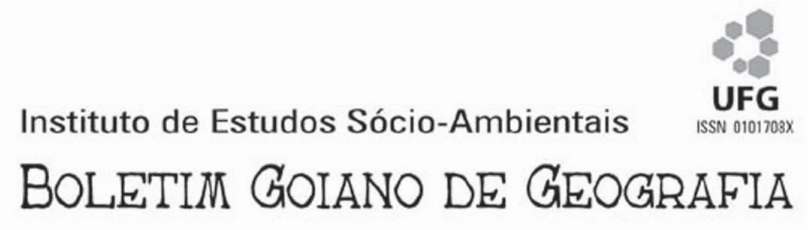

v. 26, n. 2, jul./dez. 2006

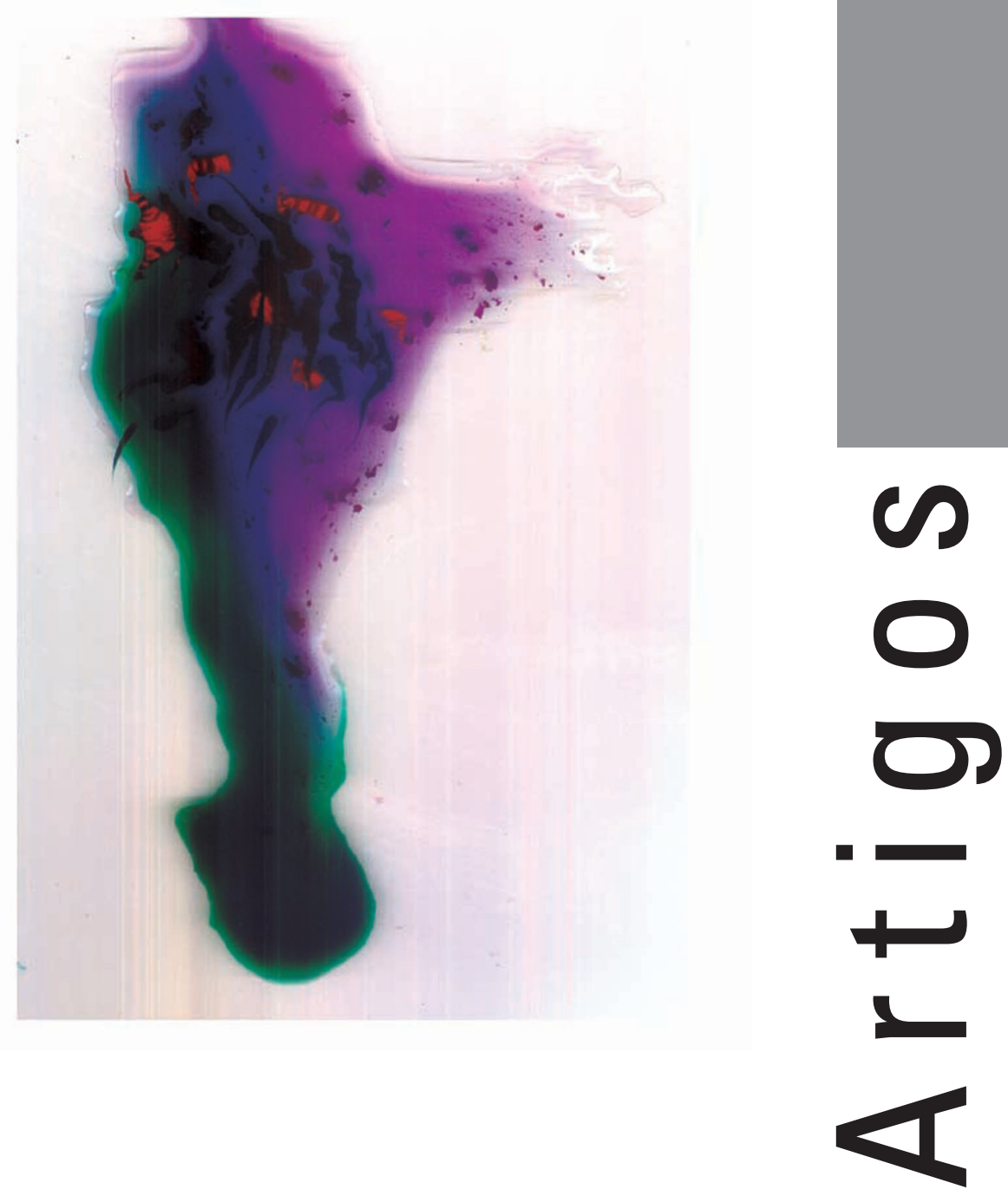




\title{
EDUCAÇÃO AMBIENTAL: ASPECTOS HISTÓRICOS E PERSPECTIVAS
}

\author{
ENVIRONMENTAL EDUCATION: \\ HISTORICAL ASPECTS AND PERSPECTIVES
}

\author{
Sandra de Fátima Oliveira - UFG \\ sanfaoli@iesa.ufg.br
}

\section{Resumo}

Neste artigo é feita uma breve abordagem sobre a evolução sócio-econômica da humanidade, aliada à educação, com 0 objetivo de possibilitar uma melhor compreensão sobre a necessidade atual de inserção da temática ambiental nas práticas educativas formal e não formal. Além disso, algumas considerações relativas às perspectivas da educação ambiental, também, são tratadas inclusive numa abordagem transdisciplinar.

Palavras-chave: sócio-econômico, evolução humana, educação ambiental, educação, transdisciplinaridade.

\begin{abstract}
In this article one brief approach on the social-economical evolution of the humanity, allied to education, with the objective to make possible one better understanding on the current necessity of thematic insertion of ambient in the educative practice formal and unformal. Moreover, some consider to the perspectives of the environmental education are boarded in the transdisciplinarid context.
\end{abstract}

Keys-words: social-economical, humam evolution, environmental education, education, transdisciplinarid. 


\section{Introdução}

Para tratar dos aspectos históricos da educação ambiental e possibilitar uma melhor compreensão da necessidade atual de inserção da dimensão ambiental nas práticas educativas tanto formal, quanto não-formal e, também, em diversas atividades da nossa vida cotidiana, foi feita uma breve abordagem sobre o processo de evolução sócio-econômica da humanidade aliado à educação. Não há pretensão de esgotar e nem de aprofundar aqui este assunto, uma vez que a intenção com este texto é reunir informações obtidas através da consulta a alguns autores e sistematizá-las, possibilitando um maior entendimento sobre o tema proposto.

Para melhor caracterizar esse processo evolutivo, considerou-se como pilares mestres desta análise a evolução humana e as relações entre ser humano/natureza, acompanhando os diferentes momentos de transformação e apropriação dos recursos naturais por parte das diversas formas de organização sócio-econômica da humanidade. Após este entendimento, serão tecidas algumas considerações relativas às perspectivas da Educação Ambiental, inclusive numa abordagem transdisciplinar.

Evolução Sócio-Econômica da Humanidade e a Educação

O ser humano entrou em cena sobre a superfície da terra quando já havia transcorrido 99,98\% da história do Universo, que é de aproximadamente 15 bilhões de anos. Há 10 milhões de anos os primatas "superiores”, que não são nossos ancestrais e sim nossos primos irmãos, viviam, segundo Boff (2002), pulando alegremente de galho em galho nas savanas africanas.

Durante milhões de anos, alguns desses grupos de primatas evoluíram e, por volta de 3 milhões, surgiram os primeiros hominidas bípedes. Apesar de já fabricarem alguns utensílios e abrigos bastante rudimentares, eles viviam como outro animal qualquer, coletando o que a natureza oferecia, ou seja, participavam da teia alimentar, do fluxo energético como todos os outros animais. Desta maneira, sua relação com a natureza estava ligada única e exclusivamente à questão da sobrevivência.

Por volta de um milhão de anos, os hominidas já eram plenamente humanos e tentavam domesticar o fogo. A partir desta época, diversos grupos humanos começaram a inventar e empregar instrumentos para suprir suas deficiências na obtenção de alimentos - passaram a caçar e pescar -, para construir abrigos e usar o fogo, dando início ao processo de independência da natureza. 
Apesar de já desempenharem papel de depredadores, as modificações produzidas pelas ações humanas não chegavam a provocar desequilíbrios ecológicos, pois todas as práticas - coleta, caça e/ou pesca - atendiam somente às necessidades básicas do grupo. A economia era de subsistência, sem retirar excedentes da natureza. Nesta fase, o meio natural mostrava ser, também, fonte de alegria, de beleza, de identidade e de inspiração para a arte, música e religião.

Há 100 mil anos diversos grupos já enterravam seus mortos com rituais e flores, e há 40 mil anos vários grupos já se comunicavam através da linguagem. Durante esta fase, a interação com a natureza, o profundo respeito pelos ritmos naturais e a percepção sofisticada que tinham dos sistemas naturais eram repassados de pai para filho. Este era o sistema educacional à época.

O maior domínio sobre a natureza se deu há 20 mil anos, quando os primeiros grupos humanos passaram a domesticar espécies, tanto animais quanto vegetais. A partir daí, iniciaram o processo de transformação dos habitats naturais em pastagens, imprimindo diversas e, em algumas regiões, profundas modificações na paisagem. Até este estágio, caracterizado pela domesticação de espécies animais e denominado por vários autores como pastoreio, os seres humanos viviam em uma sociedade sem classes, mantinham uma relação de equilíbrio com a natureza, a qual eles se sentiam pertencentes como ser biológico.

Quando os seres humanos passaram a cultivar suas espécies vegetais e a utilizar os animais como força motriz, passaram a praticar a agricultura (Período Neolítico - 11 mil anos até final da Idade Média). Praticando esta nova atividade, deram início, de modo marcante, ao controle sobre a natureza e, conseqüentemente, à degradação dos ecossistemas, transformando radicalmente sua economia, marcada agora pelo domínio no abastecimento de alimentos. Este fator levou a humanidade a superar uma grande barreira que limitava o crescimento populacional.

É claro que os grupos humanos que iniciaram a prática agrícola, primeiramente de forma itinerante e através da cultura de horta, experimentaram um trabalho mais árduo, exigindo mais conhecimento e um caráter coletivo de responsabilidades para executar diversas tarefas: faziam a seleção de plantas, a seleção de sementes, o reconhecimento de solo mais férteis e a distinção de aspectos climáticos através de orientações astronômicas, além das atividades complementares de coleta, caça e construção de instrumentos.

Através da atividade agrícola, os humanos passaram a intervir na natureza através do trabalho. Para Boff (2002), intervir é trabalhar. O trabalho 
é o meio maior de forjamento da cultura. Ela não só cria instrumentos e aparatos tecnológicos para transformar a natureza, como também suscita conteúdos da consciência, formas de sentir, de valorar, de relacionar psicológica e socialmente com os outros.

Cabe ressaltar que, segundo Diamond (2001), as atividades agrícolas não iniciaram simultaneamente em todos os grupos humanos existentes no Neolítico. Aqueles que tiveram a possibilidade e o interesse em domesticar espécies animais e vegetais, e consequentemente praticar a agricultura, eram compostos por maior número de indivíduos, e dentre eles alguns disponíveis para criar/inventar. Por isso conseguiram desenvolver tecnologias cada vez mais avançadas. Estas bases para o desenvolvimento facilitaram a vida das comunidades e possibilitaram a produção de excedentes, tanto agrícolas quanto pastoris. O excedente era trocado entre os grupos, o que permitiu a manutenção e o incremento da população e aportaram meios para o surgimento das primeiras sementes das futuras cidades, para a divisão da sociedade em classes e para o início de uma nova atividade: o comércio.

Em relação à educação, cabe salientar que durante todo o desenvolvimento sócio-econômico da humanidade até o início da prática agrícola, dava-se através de uma relação natural entre a teoria e a prática. A educação cumpria uma função essencial nessas sociedades que até então não eram divididas em classes e viviam numa relação harmônica com a natureza; faziam parte da natureza. Esta educação, de acordo com Medina (1996), tem sido chamada de funcional e caracteriza-se por ser inconsciente, por impregnação, por presença, ou seja, são sujeitos da educação todos os membros da sociedade. Um exemplo atual desse tipo de educação pode ser observado em algumas comunidades indígenas e na transmissão e aprendizagem da língua materna.

Para caracterizar como se deu a evolução do processo educativo aliada à estratificação social, citaremos como exemplo: o Mundo Grego, o Gregoromano e a Idade Média. No Mundo Grego, o sistema escravista era sustentado pelo sistema filosófico, no qual a essência humana corresponderia ao ser humano livre, que é o sujeito da Educação. Os escravos não eram livres, portanto, não eram considerados humanos. Não há contradição, os escravos continuaram sendo sujeitos de uma educação funcional e prática.

Já no Mundo Grego-Romano, a organização social já se encontrava estratificada em classes, resultando na divisão entre: o trabalho manual e intelectual, a teoria e a prática, os seres humanos que pensavam e os que faziam, salientando, desta forma, a diferença entre o conhecimento e a transformação do mundo por meio do trabalho. Esta separação exerce, até os dias 
atuais, uma influência negativa na educação, como ressalta Medina (1996). Nesta sociedade, nem todos os seus membros eram sujeitos de igual educação, pois a educação filosófica e científica praticada era privilégio de alguns e não um instrumento de toda a sociedade para conhecer, refletir, entender e transformar a realidade, o mundo.

Durante a Idade Média, tanto a cultura quanto a educação permaneceram dentro das Universidades Medievais, nelas somente tinham acesso o clero e parte da nobreza. Neste tempo, a concepção de ser humano se modificou e a divisão entre senhores e servos, alicerçada na fé religiosa, era aceita como natural. Aos servos era destinada uma educação religiosa e prática que, desta forma, obteriam o paraíso, um lugar no céu.

Os seres humanos passaram a transformar a natureza através do trabalho, esqueceram seu lugar como ser natural, começaram a perder sua identidade terrena (Morin, 2004), sua conexão com o Planeta Terra. A partir daí, houve um aumento da deterioração dos recursos naturais, com a degradação de diversos ecossistemas, principalmente aqueles representativos das áreas de cultivo. Apesar dos humanos já imprimirem estas modificações nos ecossistemas, a velocidade de regeneração da natureza se equilibrava com a velocidade e intensidade de sua exploração. Dessa forma, pode-se considerar que as relações entre ser humano/natureza ainda eram harmônicas, uma vez que havia a possibilidade de regeneração e de equilíbrio dos ecossistemas.

Do surgimento da espécie Homo sapiens até o final da Idade Média (Século XVII), as formas de economia eram, a princípio, de subsistência e agrária. Posteriormente, quando atingiram a produção de excedentes, estes passaram a ser trocados entre os grupos dando origem à economia comercial. Apesar de já haver sociedades estratificadas em classes, todo este tempo representa o período pré-capitalista da humanidade, no qual o que se produzia era repartido entre a população, não havia excedentes e nem acúmulo de capital. Se houvesse a produção de excedentes, estes poderiam tanto ser trocados, quanto abastecer as festas religiosas.

\section{$\mathbf{0}$ surgimento da indústria $\mathbf{e}$ as grandes mudanças ambientais}

A revolução industrial, final do Século XVII, foi marcada por uma drástica modificação na economia humana e um aumento acentuado na exploração desordenada da natureza. As relações econômicas entre produtores e consumidores foram substituídas aos poucos por múltiplos escalões de 
intermediários, os quais iniciaram o processo de acumulação de capital, originando um novo sistema de desenvolvimento: o capitalismo.

Neste sistema, alguns passaram a ser donos dos meios de produção, a população cresceu, se diferenciou, tornou-se sedentária. Paralelamente, a divisão de trabalho se acentuou e a exploração e o uso dos recursos naturais aumentaram tanto em qualidade quanto em quantidade, reforçando os processos de transformação, além de gerar escassez e saturação dos recursos naturais.

$\mathrm{O}$ excedente passou a ser produzido em escala cada vez mais acelerada para atender as necessidades decorrentes do aumento populacional, com níveis de exigências e de consumo cada vez maiores.

A indústria, desde seu início, utiliza os recursos naturais, assumindo parte do processo de degradação, imprimindo um ritmo conveniente para si e confia ao Planeta Terra, que atua sem desígnios pré-estabelecidos, a reconstrução desta matéria-prima transformada e a última etapa do processo de decomposição, que é a transformação dos resíduos industriais. Deste modo, a finalidade de evitar a escassez e a saturação dos recursos naturais fica prejudicada, porque a velocidade de regeneração da natureza é menor que a de consumo e produção de resíduos; conseqüentemente, a esperada renovação não acontece, pelo menos na escala de tempo desejada. O resultado é óbvio: a quantidade de matéria-prima torna-se precária e os resíduos acumulados ultrapassam a capacidade de recuperação dos ecossistemas, causando escassez e poluição. Em última instância, a indústria vem transformando os recursos naturais com uma rapidez que não favorece a sua renovação, e nem sequer o próprio consumo. O impacto sobre o Planeta Terra atingiu proporções gigantescas.

Nesta época, com todas as suas características especiais, produziu-se uma mudança qualitativa tanto nas formas de relação do ser humano com a natureza quanto dos seres humanos entre si, modificando-se totalmente as relações de trabalho, passando de um sistema feudal ao contratual, alicerçado na exploração humana e da natureza.

Para responder a essa nova necessidade, ou seja, a de transformar a sociedade feudal em contratual criou-se a escola pública, cuja ideologia era reformar a sociedade, pregando a igualdade entre os humanos, a fraternidade, a liberdade. Estes eram os postulados da democracia burguesa que perfilava como classe revolucionária. Neste novo modelo de educação, fruto da revolução industrial, do avanço do conhecimento científico e do aparecimento de novas formas de produção capitalista, todos os membros da sociedade seriam, teoricamente, sujeitos de igual educação. 
Surgiu, então, a idéia, fundamentada na democracia burguesa, de escolarizar a todos como necessidade do mercado de trabalho, tornando a educação pública um fenômeno político e reprodutor das relações econômicas de produção, preparando a mão de obra que o capital exigia para seu desenvolvimento.

A educação pública, fruto dessa nova estrutura social tinha, conforme Saviani (1988), o mestre como o soberano na escola, porém era o servidor das estruturas socioeconômicas capitalistas. Surgiu como produto da escola pública a pedagogia da essência, com sua relação autoritária entre educando e educador que responde à mesma estrutura social de dominação: dono de produção e classe trabalhadora que vende sua força de trabalho. Os docentes reproduziam as idéias da classe dominante como se fossem as idéias do conjunto da sociedade.

Esta escola pública mostrava claramente uma contradição, pois desempenhava um papel reprodutor das condições sociais vigentes ainda não resolvidas, como afirma Medina (1996).

Os seres humanos se tornaram cada vez mais afastados e distantes da natureza, muitos perderam totalmente sua identidade terrena, característica ainda presente nos servos. A Terra, antes tida como orgânica, passa a ser compreendida como uma máquina fornecedora de matéria-prima, para ser dominada.

O processo de urbanização, representado como remanescente rural e emergente da revolução industrial, caracterizou-se, desde seu surgimento, como um centro consumidor especializado em recursos naturais. Atualmente, a cidade grande dá às pessoas a impressão de liberação total da natureza. Suas necessidades em termos de energia, alimentação, comércio, entre outras, parecem ser satisfeitas a partir do espaço determinado e por elementos que nada devem aos recursos naturais, chegando até a configurar a falsa alienação do humano urbano, do ambiente natural ao qual ele também pertence.

A urbanização vislumbrava criar um ambiente humano, procurando delinear a organização e funcionamento do espaço social, em uma tentativa de minimizar os impactos deste contexto. Entretanto, tudo indica que esta consonância está longe de ser alcançada, principalmente quando se observa que as intervenções antrópicas são impostas por um processo de organização das atividades produtivas, baseadas no consumo, no qual os fatores ecológicos contrapõem aos fatores econômicos como um dos determinantes mais importantes na intervenção da natureza. 
Nesta era industrial, caracterizada por uma economia capitalista, na qual se produz excedente e acumulação de capital através da mais valia gerada pelo trabalho operário e pela apropriação privada dos recursos naturais, é liderada por uma única norma: a de obter maior lucro em menor tempo possível. Neste sistema se repartem socialmente os custos dos danos ambientais e são apropriados, privadamente, benefícios da exploração da natureza e do trabalho humano. Este processo foi e continua sendo acompanhado pela urbanização acelerada e desordenada, principalmente nos países pobres.

Quando o capitalismo se consolida como sistema de desenvolvimento e a burguesia como sua classe dominante que necessitava se manter no poder, a pedagogia da essência que se fundamentava, mesmo que teoricamente, na igualdade entre os sujeitos da educação, passa a não servir mais. Uma vez que podia fornecer instrumentos para a compreensão, interpretação e transformação do mundo através da transmissão do conhecimento acumulado pela humanidade. Isso não interessava às bases da sociedade capitalista.

No início do século XX realizou-se uma reformulação da escola, surgiu a Escola Nova, que acabou sendo reduzida a uma pedagogia da existência, fundamentada nas desigualdades e mais uma vez mantenedora das bases sociais capitalistas. Com a Escola Nova começou o processo de degradação da escola pública e da desvalorização social da categoria docente.

Os sistemas educacionais públicos não se adequaram às idéias da Escola Nova, especialmente na América Latina, resultando em grandes prejuízos para a educação das classes menos favorecidas pelo sistema. Por outro lado, a educação das elites melhorou, pois somente as escolas privadas tinham estrutura e equipamentos suficientes para desenvolverem com êxito a metodologia da Escola Nova. Desta forma, a educação atuou como mecanismo de recomposição da hegemonia burguesa, coincidindo historicamente com a expansão capitalista, que começa na América Latina na década de 1930, chegando ao seu ápice na década de 1960.

Coincidindo ainda com a expansão capitalista, a divisão internacional do trabalho e o surgimento das multinacionais, com seus processos de homogeneização do consumo como necessidade de ampliação dos mercados e a transferência de padrões culturais, surgiu na educação a Pedagogia Tecnicista, na primeira metade do século XX. Esta sustentava que o processo educativo deveria ser objetivo e operacional - igual ao trabalho fabril - no qual se destaca o papel do planejamento como elemento fundamental. A educação tornou-se mecanizada e os meios utilizados eram determinados exteriormente pelos sistemas econômico e social dominante. Surgem metodologias 
educativas como: ensino por TV, ensino programado, a indústria do livro didático. Observa-se aí um maior aprofundamento do processo de desvalorização da atividade docente, que se transforma em um executor de planos elaborados por pessoas, muitas vezes alheias ao sistema educacional.

Nesta época, o avanço do imperialismo internacional, as relações entre os seres humanos e a natureza apresentam evidentes sintomas de deterioração, o que levou a uma tomada de consciência social dos primeiros problemas graves.

A divisão do mundo em países centrais e periféricos retrata a situação atual, caracterizada pela Revolução Científico-Tecnológica e consequentemente pela divisão internacional do trabalho que reflete uma distinção entre o pensar e o fazer. A educação também reflete esta situação.

Os países centrais/desenvolvidos produzem e criam conhecimentos, têm uma ótima educação destinada às elites e centralizam todos os processos de investigação técnico-científico mais especializados. Enquanto que nos periféricos nota-se uma crescente deterioração da educação como um todo e em especial aquela destinada às classes populares, a qual, segundo Medina (1996 e 2002), se limita à reprodução de conhecimentos. Já as camadas médias têm acesso a uma reduzida e controlada educação técno-científica, impregnada da fragmentação imposta pelo paradigma positivista e sua racionalidade instrumental e econômica, com seus estreitos e limitados pontos de vista.

\section{Os loucos anos 1960, suas repercussões e o surgimento da educação ambiental}

As grandes manifestações dos anos 1960 pregaram novos modos de sentir, agir e pensar, pela liberalização da mulher, em favor dos negros e também pelas questões ambientais e da educação, criticando a educação tradicional e as teorias tecnicistas que visavam a formação de indivíduos eficientes e eficazes para o mundo do trabalho e para o consumo. É que o paradigma positivista da ciência já não conseguia mais dar resposta aos novos problemas, caracterizados pela complexidade que envolve as questões ambientais. No início da década de 1960, os problemas ambientais, motivados modelo de desenvolvimento, mostravam a irracionalidade do sistema econômico, mas não se falava em educação ambiental.

De acordo com diversos autores, a expressão educação ambiental foi pela primeira vez colocada, em 1965, numa Conferência de Educação da Universidade de Keele, Inglaterra. Além disso, houve a recomendação de 
que esta educação ambiental deveria se tornar uma parte essencial da educação de todos os cidadãos. Contudo, esta educação ambiental era definida como conservação ou ecologia aplicada, e a disciplina para a sua inserção seria a biologia.

Um fato interessante aconteceu em 1968, a UNESCO realizou um estudo sobre meio ambiente e a escola entre seus países membros e concluiu que a educação ambiental não deveria constituir-se numa disciplina específica, tendo em vista a complexidade que envolve as questões ambientais.

Neste mesmo ano, o Clube de Roma ${ }^{1}$ começou a se reunir e em 1972 um dos relatórios resultado desta tarefa foi publicado. Este relatório intitulado "Os Limites do Crescimento" trouxe um modelo inédito para a análise do que poderia acontecer se a humanidade não mudasse seus métodos econômicos e políticos, ou seja, caso se mantivesse o ritmo de crescimento a qualquer custo, sem levar em conta os aspectos ecológico e social chegaríamos ao limite do crescimento, ou na pior das hipóteses, ao colapso.

Como resultado dos agitados anos 60 e do relatório Limites do Crescimento, a ONU organizou e realizou em 1972, na cidade de Estocolmo, a $1^{\text {a }}$ Conferência sobre Meio Ambiente Humano. Nesta conferência a temática central girou em torno da possibilidade de esgotamento do petróleo, uma vez que estávamos no meio da crise desse recurso e de outros não renováveis. Além deste tema, a questão da educação ambiental também foi abordada, inclusive com a proposta de criação do programa internacional de educação ambiental. Este somente foi somente foi formalizado em 1975 no Seminário sobre Educação Ambiental que aconteceu em Belgrado.

O grande marco mundial sobre educação ambiental foi a $1^{\text {a }}$. Conferência Intergovernamental de Educação Ambiental, realizada no ano de 1977, em Tibilisi, na Geórgia (ex-URSS). Foi desta conferência que saíram as definições, os objetivos, os princípios e as estratégias para a educação ambiental, que ainda são adotados como referencial por muitos educadores.

A década de 1980, apesar dos grandes transtornos na economia e dos tristes recordes em tamanho de acidentes ambientais, foi marcada por uma consciência generalizada de que os problemas ambientais não afetam a um ou outro país isoladamente ${ }^{2}$, sendo que transcendem os limites geopolíticos. Quando se refere a eles, devemos considerar o Planeta Terra como uma totalidade em movimento, onde a modificação, a deterioração ou a exaustão dos recursos naturais ou a transformação dos ecossistemas, não atingem somente um grupo social, em cujo espaço geográfico se produz, mas sua repercussão se dá na totalidade do sistema. 
Nos países desenvolvidos e nos organismos internacionais, surgiu a preocupação e a necessidade pela busca de soluções. Já nos países subdesenvolvidos a preocupação central era como encontrar estilos de desenvolvimento que não conduzissem aos mesmos erros cometidos pelos países desenvolvidos, porém que permitissem a superação de suas crises estruturais de pobreza, analfabetismo, falta de saneamento, dentre outros.

No Brasil, na década de 1980, os setores da educação e meio ambiente ganharam grandes avanços, conseguindo as bases legais para a união oficial entre a educação e a defesa do meio ambiente. O país ganhou novas leis ambientais, as quais incluíram a obrigatoriedade da educação ambiental em todos os níveis de ensino, como: Lei n ${ }^{\circ}$ 6.938/81 que institui a Política Nacional do Meio Ambiente e a Constituição Federal de 1988, com seu Capítulo 225 sobre meio ambiente.

A década de 1990 iniciou-se com a realização da Conferência sobre Meio Ambiente e Desenvolvimento - Rio/92 e do fórum global. Neste eventos foram elaborados documentos importantes que estão entre as principais referências para quem quer praticar educação ambiental: Agenda 21, A Carta da Terra, A Carta Brasileira para Educação Ambiental e o Tratado de Educação Ambiental para Sociedades Sustentáveis. Além disso, ainda nesta década aconteceu a $2^{\mathrm{a}}$. Conferência Intergovernamental sobre Educação Ambiental na Grécia, em 1997.

No Brasil, em 1994, iniciou-se a elaboração do Programa Nacional de Educação Ambiental (PRONEA) e em 1997 os Parâmetros Curriculares Nacionais (PCNs) foram concluídos. Nestes últimos é indicada a inclusão da educação ambiental no currículo das séries iniciais de forma transversal. Isso, de acordo com Medina (2002), implica na introdução de um processo de inovação educativa, que envolve tanto professores quanto estudantes e comunidade, comprometendo ao mesmo tempo as instâncias decisórias e responsáveis, como as secretarias de educação estaduais e municipais. As universidades, como instituições responsáveis pela formação de professores para o ensino básico, não podem permanecer alheias às novas necessidades sociais.

Em 2002 foi regulamentada a Lei da Política Nacional de Educação Ambiental, através do Decreto 4.281 do poder executivo. Esta lei, em seu Artigo V, trata da inclusão da educação ambiental em todos os níveis de ensino, especificando seus princípios gerais e as competências dos órgãos públicos e privados e, o Artigo VI, trata dos programas de educação ambiental integrados às diversas atividades que envolvem a questão ambiental. 


\section{As perspectivas da Educação Ambiental}

O ser humano perdeu suas identidades biológica e cultural ao longo de sua história evolutiva sócio-econômica. Encontramo-nos atolados numa crise que é tanto cultural e científica, quanto de pensamento, principalmente quando começou a emergir a intuição, a desconfiança e a tomada de consciência de que o modelo cartesiano de pensar começa a esgotar as estratégias que moldaram um ser humano dolorosamente fraturado e permitiram imaginar o mundo pautado pela tirania da ordem.

Capra (1986 apud Almeida, 2002) sugere que uma tal crise do pensamento articula-se e decorre de uma crise muito maior que tem por suporte três fenômenos: a ameaça de esgotamento dos recursos energéticos do planeta, a contestação do modelo patriarcal de condução da sociedade e, por fim, uma crise generalizada da cultura. Para Almeida (2002), Edgar Morin pisa mais forte nesse terreno movediço e responsabiliza a casta intelectualizada moderna por parte dos males sociais do nosso tempo. Todo pensamento redutor implica políticas sociais redutoras, parciais, cerceadoras das potencialidades e liberdades humanas.

A educação, então, deverá liberar-se da fragmentação imposta pelo cartesianismo através do paradigma positivista da ciência e sua racionalidade instrumental e econômica, além dos seus estreitos pontos de vista.

Com relação aos novos rumos da EA para a sociedade deste século, acredita-se que deverá haver a incorporação de novos conceitos característicos do pensamento científico contemporâneo e a superação das visões reducionistas que se manifestam na vertente naturalista da EA. Estas visões ingênuas têm no máximo conduzido a processos de sensibilização dos sujeitos e não provocam modificações profundas de comportamento, atitudes e hábitos.

Há a necessidade de uma teoria pedagógica consistente, baseada na construção coletiva do conhecimento, na ação reflexiva e consciente e nas mudanças éticas de comportamento tendentes a concretizar processos de tomada de decisões, participativos e democráticos por toda comunidade. Além disso, a EA deverá possibilitar o desenvolvimento afetivo e humano e a passagem da ética antropocêntrica para a ética biocêntrica para o exercício pleno da solidariedade, da cidadania, incorporando na mente e no coração humanos as suas identidades cósmica, terrena, biológica e cultural, conforme propõe Morin (2002).

Para Medina (1996 e 2002), a EA deve ser entendida como um processo que consiste em propiciar às pessoas uma compreensão crítica e global 
das questões ambientais. Além de elucidar valores e desenvolver atitudes que lhes permitam adotar uma posição crítica e participativa a respeito das questões relacionadas com a conservação e adequada utilização dos recursos naturais, para a melhoria da qualidade de viver dos organismos da Terra e a eliminação da pobreza extrema e do consumismo desenfreado.

Deve visar a construção de relações sociais, econômicas e culturais capazes de respeitar e incorporar as diferenças, como: opção sexual, minorias éticas, populações tradicionais, perspectivas das mulheres e a liberdade para decidir caminhos alternativos de desenvolvimento.

Para Sato (2001), há a necessidade de se definir a identidade de quem atua na área da educação ambiental. Não aquela identidade simbólica de expressar o estado da alma, a qual tem a indecisão flutuante dos sonhos, mas uma identidade política que se consolide nas ações quotidianas, que se enraíze em pensamentos constantes e que, efetivamente, seja capaz de ousar a transformação necessária para o caminho adiante.Para Oliveira et alli (2006), a educação ambiental deve apresentar-se numa abordagem transdisciplinar, pois esta propicia o desenvolvimento de uma atitude de paz, de um pensamento ambiental orientado para a sustentabilidade da Vida e da ação humana individual, comprometida com seu contexto concreto local. A integridade planetária coloca a necessidade de cuidado com cada um dos elementos que compõem a teia da vida - água, mantendo seu ciclo em qualidade e quantidade; solo, conservando sua integralidade física e biológica; ar, mantendo sua pureza e renovação. Tudo isso está relacionado à capacidade dos grupos humanos de adotarem formas de reprodução condizentes com os recursos naturais de cada região e da escolha de tecnologias conscientes e apropriadas à natureza, à comunidade e a sua cultura. O que exige de cada ser humano um repensar sobre o modo como se relaciona consigo mesmo, com os outros e com a natureza em suas atividades produtivas numa nova cosmovisão centrada no significado da vida e numa atitude ética alicerçada nos princípios biocêntricos.

O desenvolvimento de uma atitude transdisciplinar promove a percepção sistêmica da vida, a compreensão da unidade que permeia toda diversidade, orientando uma prática afetiva e comprometida com a sustentabilidade planetária. Dessa forma, a sustentabilidade ecológica, social e econômica é conseqüência de uma ação transdisciplinar que abarca vários níveis da ação humana, formando um individuo responsável e co-criador da realidade - um individuo que responde por suas ações e por seu desenvolvimento pessoal em consonância com a natureza, promovendo, assim, sua realização pessoal ao mesmo tempo em que promove o Bem Comum e a Vida. 
As bases para esta proposta, elaborada por Oliveira et alli.(2006), foram obtidas no mais novo relatório intitulado "Educação: um Tesouro a descobrir" apresentado, em 2000, pela "Comissão Internacional sobre Educação para o Século XXI", ligada à UNESCO e presidida por Jaques Delors. Este relatório enfatiza claramente os quatro pilares de um novo tipo de educação: aprender a conhecer, aprender a fazer, aprender a conviver e aprender a ser. A abordagem transdisciplinar dada pelos autores supra citados pode, segundo Nicolescu (2000 e 2005) ter uma contribuição importante no advento deste novo tipo de educação - educação ambiental para a sustentabilidade.

\section{Conclusão}

A educação ambiental deverá responder ao desafio ambiental contemporâneo por meio da compreensão de uma mudança radical dos valores da sociedade atual e da necessidade de sua urgente transformação, para assegurar a própria sobrevivência da espécie humana e da vida em todas suas dimensões. É necessária uma transformação fundamental na maneira de cada um pensar de si, o meio, a sociedade e o futuro; uma transformação básica nos valores e crenças que orientam pensamentos e ações; uma mudança que permita adquirir uma percepção mais complexa da realidade com postura ética, responsável e solidária.

Para que haja a inserção da educação ambiental no processo educativo brasileiro são necessárias grandes mudanças no ensino superior, formador dos formadores, pois ele ainda encontra-se sustentado na fragmentação do conhecimento e ainda ancorado na disciplinaridade. Além disso, é preciso vontade política por parte de nossos governantes, colocando a educação ambiental no orçamento e realizando as políticas públicas voltadas para sua implementação no Brasil.

\section{Notas}

1 Denominação atribuída a um grupo de 30 indivíduos com diversas formações e profissões e originários de dez países que se reuniram na cidade de Roma para debater a crise atual e futura da humanidade.

2 Resultado do Relatório Nosso Futuro Comum elaborado pela Comissão Brundtland em 1986. Neste relatório, que apresenta um diagnóstico ambiental do mundo, são apresentadas estratégias para se alcançar o desenvolvimento sustentável. Os resultados deste relatório levou a ONU a realizar a Conferência sobre meio ambiente e desenvolvimento - Rio-eco/92. 


\section{Referências}

ALMEIDA, M. C. Complexidade, do casulo à borboleta. In: CASTRO, G. et al. (Orgs.). Ensaios de complexidade. Porto Alegre: Sulina, 2002.

BOFF, L. Identidade e complexidade. In: CASTRO, G. et al. (Orgs.). Ensaios de complexidade. Porto Alegre: Sulina, 2002.

DELORS, J. (Org.). Educação: um tesouro a descobrir. São Paulo: Cortez; Brasília: MEC/UNES$\mathrm{CO}, 2000$.

DIAMOND, J. Armas, germes e aço. Rio de Janeiro: Record, 2001.

MEDINA, N. M. Relações históricas entre sociedade, ambiente e educação. Pub. Esp. MEC, Brasília, 1996.

MEDINA, N. M. Educação ambiental para o Século XXI. IBAMA, MMA, Brasília, 1997.

MEDINA, N. M. Os desafios da formação de formadores para a educação ambiental. In: PHLIPPI Jr., A e PELICIONI, M. C. F. (Orgs.). Educação ambiental: desenvolvimento de cursos e projetos. 2. ed. São Paulo: Signus, 2002.

MORIN, E. \& KERN A. Terra pátria. 3. ed. Porto Alegre: Sulina, 2002.

NICOLESCU, B. Um novo tipo de conhecimento - transdisciplinaridade. In: SOMMERMAN, A.; MELLO, M. F. \& BARROS, V. M. (Orgs.). Educação e transdisciplinaridade I. 2. ed. São Paulo: Triom, 2000.

NICOLESCU, B. Manifesto da transdisciplinaridade. 3. ed. São Paulo: Triom, 2005.

OLIVEIRA, S. de F.; VIANA, R. M. \& HOEFFEL, J. L. de M. Reverência pela vida: atitude transdisciplinar na educação ambiental. In: VI CONGRESSO IBEROAMERICANO DE EDUCAÇÃO AMBIENTAL, Joinville. Anais... Joinville: MMA/MEC/, 2006.

SATO, M. Apaixonadamente pesquisadora em educação ambiental. Revista educação: teoria e prática, UNESP, Rio Claro, 9(16): 24-35, 2001.

SAVIANI, D. R. et all. Desenvolvimento e educação na América Latina. Cortez, São Paulo: 1988.

SANDRA DE FÁTIMA OLIVEIRA - Doutora em geociências pela USP e professora do curso de geografia da Universidade Federal de Goiás.

Recebido para publicação em outubro de 2006

Aceito para publicação em novembro de 2006 